\title{
ENTREVISTA COM VICTOR CARVALHO PINTO
}

\section{Entrevistado:}

\section{Victor Carvalho Pinto}

Doutor em Direito Econômico e Financeiro pela Universidade de São Paulo. Consultor Legislativo do Senado Federal. Coordenador do Núcleo Cidade e Regulação do Laboratório Arq.Futuro de Cidades do Insper.

\section{Entrevistadores:}

\section{Betânia Alfonsin}

Doutora em Planejamento Urbano e Regional pelo Instituto de Pesquisa e Planejamento Urbano (IPPUR) da UFRJ (2008). Professora da Faculdade de Direito e do Mestrado em Direito da Fundação Escola Superior do Ministério Público do RS, instituição na qual coordena Grupo de Pesquisa em Direito Urbanístico e Direito à cidade.

\section{Nelson Saule Júnior}

Doutor em Direito do Estado pela Pontifícia Universidade Católica de São Paulo . Professor do curso de graduação em Direito e do núcleo de direito urbanístico do PPGD da PUCSP. É Coordenador da Área de Direito à Cidade do Pólis - Instituto de Estudos, Formação e Assessoria em Políticas Sociais.

Nelson Saule Júnior: Quais são as conexões e os impactos do tratamento constitucional da política urbana no conteúdo do Estatuto da Cidade?

Victor Carvalho Pinto: A gente às vezes pensa que criou algumas ideias, mas na verdade absorvemos de gerações e trabalhos anteriores. Por isso, eu trago à lembrança o Projeto de Lei 775, de 1983. Muito do que a gente discute até hoje tem origem naquele esforço. E não fomos nós que começamos, foram outras pessoas. Eu recentemente peguei o projeto e reli, ponto a ponto. Para a minha surpresa encontrei acho umas dez frases que então praticamente transcritas no Estatuto da Cidade. Então, como uma coisa que eu já intuía, percebi que existe um conjunto de ideias que é mais ou menos consensual, que foi se formando e vai além de nós que éramos do campo da Reforma Urbana na época. É um conjunto de ideias que nasce muito na prefeitura de São Paulo, muitos urbanistas, geraram um senso comum, digamos assim, urbanístico, principalmente na questão fundiária, a questão da renda da terra, a questão da recuperação da valorização imobiliária, da separação do direito de propriedade e do direito de construir. Eu acho que a questão do planejamento urbano já não era tão consensual, quer dizer, os urbanistas em geral, mais tradicionais, sempre defenderam o Plano Diretor e tal e nós não tínhamos uma posição muito clara, éramos mais ou menos contra, pelo viés tecnocrático, mas nunca se teve uma formulação muito completa do assunto. Então eu acho que esse senso comum, de certa maneira, entrou para a Constituição. No Projeto 775, tinha toda uma polêmica sobre se a União poderia legislar sobre direito urbanístico, tanto é que eles juntaram lá, pareceres do Hely Lopes Meirelles e do Miguel Reale só para dizer que sim, que a União poderia legislar sobre Direito urbanístico. Eu não tenho muita dúvida de que o artigo 24, I, da Constituição Federal é uma resposta a isso. Entrou bem explícito no texto 
constitucional, para ninguém ter dúvida. Se você pegar aqueles pareceres, você vai ver que também tinha um questionamento sobre o alcance do direito de propriedade. Se perguntava se o texto poderia ter essas restrições todas, essas regulamentações, se isso violaria o direito de propriedade. Você vê que os pareceres também se dedicaram a explicar que não, que existe a função social da propriedade, etc. E isso entrou na Constituição em quatro momentos, nos direitos fundamentais, na ordem econômica, no urbano, e no agrário também. Então eu vejo a Constituição, de certa maneira, refletindo essas preocupações que já existiam na época. O Estatuto da Cidade, veio na sequência, numa continuidade. Tanto é que, num primeiro momento, teve aquele projeto de lei do Raul Ferraz ${ }^{1}$ e ele simplesmente pegou o 775 e atualizou rapidamente com relação à Constituição. A gente passou muitos anos discutindo o projeto de lei do Raul Ferraz entre a Constituição e a promulgação do Estatuto.

Betânia Alfonsin - Gostaríamos que você falasse um pouco sobre o contexto desse momento entre a Constituição e o Estatuto: quais eram os processos que estavam em curso, quais eram os movimentos e questões políticas que estavam colocadas naquele momento.

Victor Carvalho Pinto - A sociedade é muito mais ampla do que nós, então a gente só vê um pedacinho da realidade. Logo em seguida da Constituição, o PL 775, continua em tramitação. Ele só parou de tramitar em 1995, quando o governo retirou. Mas aí foram se juntando vários outros projetos, todos muito parecidos. Esse do Raul Ferraz, se não me engano, contava com o apoio do urbanista Candido Malta Campos Filho. Algumas pessoas na época participavam muito e de alguma maneira eram consultadas, ou pelo governo ou por deputados, como o Paulo Lomar e a Claudia Dutra. A Claudia é a pioneira total, porque ela estava lá no Ministério quando foram redigidas as primeiras minutas do que depois se tornou o PL 775. Esse projeto estava numa tramitação lenta na Câmara e aí teve um momento muito importante, mas pouco documentado, em 1994, quando o deputado Nilmário Miranda, em um certo momento assumiu a relatoria do projeto e teve a ideia de constituir um grupo de trabalho, com vários interlocutores para buscar um consenso. Eu participei desse grupo de trabalho, que deve ter durado uns seis meses, mais ou menos, com uma reunião por mês na Câmara dos Deputados. Tinha representantes da área do desenvolvimento urbano do governo, Diana Meirelles da Mota, da área de ordenamento territorial do governo, Thereza Cristina Carvalho, Câmara Brasileira da Construção Civil, doutor Vicente Amadei, Vera Ribeiro, assessora da bancada do PT, eu estava pelo movimento da Reforma Urbana e a Suely Araújo pela Consultoria Legislativa da Câmara dos Deputados.

Era frequente que eu o doutor Vicente chegássemos cedo e ficássemos esperando os demais. Ele vinha de fora de Brasília, direto do aeroporto e eu já estava aqui. Isso criou uma certa proximidade entre mim e ele. Nesses encontros eu sempre tentava explicar para ele, que representava a construção civil, que esse tipo de lei existe no mundo inteiro, que não era comunista, que não iria desrespeitar o direito de propriedade, que era só botar ordem no desenvolvimento urbano e que até iria ser bom para eles também porque iria desovar os terrenos, esses terrenos que os proprietários não querem vender. Então a gente conversava muito, porque ele foi proprietário ou gerente de uma empresa de loteamentos populares em São Paulo e contava, assim, entusiasmadíssimo, sobre os loteamentos que tinha feito e como em poucos dias vendia tudo, para pessoas pobres, que compravam para também ter uma chance de morar, e que eles trabalhavam dentro da lei, o que era bom para a cidade. Nesse processo de apro- 
ximação, teve um dia que eu o convidei ele para vir no INESC, acho que isso é importante explicar, eu estava participando pelo movimento da Reforma Urbana, mas através do INESC, que é um ONG importante sediada em Brasília, onde eu trabalhava.

A gente não tinha muita comunicação porque não havia internet e eu também não fiz relatórios. Enfim, estava em Brasília isolado e a passagem de avião custava uma fortuna na época. Naquela época também, do movimento, por exemplo, tinha o Wladimir Ribeiro, que era assessor do próprio deputado e representou o movimento no comitê gestor do fundo de garantia. O doutor Vicente veio no INESC, expliquei o que é uma ONG, qual era o nosso trabalho. Ele me convidou para ir no SECOVI, em São Paulo, onde fui recebido para um almoço. Naquela época o grande assunto era o parcelamento ou edificação compulsórios (PEUC). Ele não queria que colocasse diretrizes de regularização fundiária no Estatuto da Cidade, já que ele achava que desenvolvimento urbano tinha que ser dentro da lei. Aí eu falei "olha doutor Vicente, esse é um ponto que a gente não tem como negociar, eu estou aqui para isso, então se não entrar regularização fundiária a gente não vai poder apoiar”. Enfim, teve no (PEUC) uma redação proposta por ele que falava assim, você não pode obrigar a empresa ou o proprietário a fazer alguma coisa que não tem demanda, de repente a prefeitura obriga a gente a fazer uma coisa que não tem para quem vender, a gente tem que ter a demanda, não posso ser obrigado a fazer uma coisa que não tem demanda. Não, é razoável e tal. Então tem esses pequenos detalhes assim que foram entrando. No fundo, o atual (PEUC) é razoavelmente diferente do que se tinha proposto. Até tem uns pedaços lá que foram propostas nossas e outras coisas que não entraram. E muita coisa, assim, grande parte das coisas foram passando batido. Agora tem uma coisa importante que eu preciso também deixar registrado, esse grupo de trabalho trabalhou em cima de uma minuta que o Ministério tinha preparado a partir dos projetos anteriores, elaboradas por consultores. Mas foram sendo feitos pequenos ajustes. Enfim, aí o que acontece? Esse grupo estava andando em certo momento o deputado Luiz Roberto Ponte, do Rio Grande do Sul, que era o presidente da (CBIC), na época, conseguiu pedir audiência do projeto na Comissão de Economia, Indústria e Comércio e lá assumiu a relatoria e segurou por muito tempo. Vale lembrar que ele também teve uma presença importante na própria Constituinte.

Aí o deputado Nilmário pegou o resultado do grupo de trabalho e apresentou como projeto dele 2 . Inclusive ele cita lá no final, explica que a origem foi o grupo de trabalho e tal. Mas aí o projeto ficou lá com o deputado Ponte, mas ficou sei lá quanto tempo, uns cinco anos. Foi muito, muito tempo. Eu estive lá, eu estive com o deputado pedindo para ele liberar, enfim, a gente fez o que pôde para tentar convencê-lo a relatar.

Mas o importante é que a coisa foi andando para frente com o relatório apresentado, mas a partir daí eu não estava mais acompanhando cotidianamente. O que eu lembro é que foi para a área de meio ambiente, aí tinha lá o Fábio Feldmann também colocou algumas coisas ambientais e depois o, Inácio Arruda fez várias audiências públicas e incorporou muitas coisas como relator na Comissão de Desenvolvimento Urbano. Acho que ele foi um grande aliado do movimento da Reforma Urbana.

Agora tem que também explicar uma coisa que muitas vezes eu já vi pessoas aí fazendo até artigos e teses, pegando simplesmente a tramitação formal do Estatuto da Cidade e tem muita coisa que as pessoas acabam não percebendo. Então, o que acontece, enquanto a gente estava lá na Câmara discutindo 
tudo isso, o Senado aprovou o projeto de lei Estatuto da Cidade e a gente foi pego de surpresa, a gente nem sabia que havia essa discussão no Senado. E aí então esse projeto, por força do regimento interno da Câmara, passou a ser o projeto líder porque a essa altura tinha dezenas de projetos já apensados, vários e vários projetos, todos parecidos uns com os outros, já apensados. Então o projeto do Senado passou a ser o projeto líder, mas se decidiu continuar a discussão na Câmara tomando como base os projetos existentes, no fundo todos derivados, direta ou indiretamente, do 775. Depois se incorpora o resultado como substitutivo do projeto do Senado. O projeto do Senado, assim, praticamente não teve influência, a meu ver. Então sem desmerecer o trabalho, no mundo da política, não teve grande influência técnica.

Agora, depois que Câmara aprovou, veio para o Senado. Eu fui na audiência pública da comissão e depois na própria sessão do plenário e o clima era muito de festa. Chegou-se a um consenso, não tem ninguém contra. O único lado que eu destacaria que é interessante é que o plenário do Senado fez uma grande sessão solene, digamos assim, para aprovação. Teve vários discursos, de vários partidos, todo mundo elogiando, comemorando, com uma única exceção que foi o discurso foi do senador Roberto Requião, do Paraná. Ele falou no sentido de que era muito retórico e de que eram boas intenções, mas que dificilmente iria realmente influenciar a política, a administração pública, que a gente iria ficar meio frustrado depois de alguns anos. Eu até querendo localizar esse discurso. Se eu me lembro, foi de improviso, ele era um ótimo orador.

Nelson Saule Júnior - Então, eu queria aproveitar porque eu acho que você já abordou bem essa parte da Constituição. Duas coisas, já depois de vinte anos, na sua opinião que matérias e instrumentos se destacam de forma positiva e negativa do Estatuto da Cidade? E se você acha que, com que, como você mesmo falou, foi lá celebrado no Senado, festa, tudo e todo mundo celebrou na época, mas o que era esperado de fato do Estatuto, você analisando todo o decorrer da sua implementação nesses vinte anos, ele cumpriu com o esperado ou não?

Victor Carvalho Pinto - Olha eu acho que as diretrizes são boas, elas criaram um campo retórico a que a gente pode sempre se referir. Representa um pouco esse consenso que de fato existe. Grande parte dessas diretrizes já estavam lá no PL 775, se vocês forem ver, muitas delas já estavam lá. Entraram no projeto outras coisas mais modernas também, mais ambientais, eu acho que foram coisas boas. Agora eu acho que a outorga onerosa do direito de construir talvez tenha sido a grande bola dentro, por mais que poucos municípios a tenham implementado bem. Mas até então era uma das grandes batalhas, da separação do direito de construir com relação ao direito de propriedade. Em geral tinha até um artigo nessas minutas dizendo isso. Não entrou na forma daquele artigo, mas entrou na forma de um instituto jurídico, com começo, meio e fim. Do ponto de vista conceitual, isso ficou bem estabelecido e depois teve o acórdão do Supremo ${ }^{3}$, relatado pelo ministro Eros Grau, que garantiu que de fato isso era perfeitamente constitucional etc. Eu acho que é um grande avanço conceitual.

Por mais que eu saiba que muita gente não gosta, mas eu considero um avanço a questão da operação da operação urbana consorciada, em grande medida porque o pressuposto dela é a mesma coisa, quer dizer, o pressuposto é que você vai vender direito de construir. Então você não vai dar de graça o direito de construir para ninguém, você vai estar cobrando uma contrapartida, só que essa contra- 
partida é amarrada em um projeto urbanístico, o uso dela é para este projeto urbanístico, se o projeto urbanístico é ruim, a operação vai ser ruim. Mas conceitualmente eu achei uma coisa boa, necessária. Você não vai fazer desenvolvimento urbano só redistributivo, quer dizer, você não vai arrecadar as coisas só para realocar em áreas carentes da cidade. Às vezes você tem que arrecadar para investir na própria área que você está arrecadando, até como forma de aumentar o quanto você pode arrecadar, criar um ciclo virtuoso, digamos assim, principalmente para áreas degradadas etc. Então se você for ver quantitativamente, financeiramente, o quanto o Brasil arrecadou de CEPAC é uma coisa extraordinária em escala mundial, o que São Paulo arrecadou, o que o Rio de Janeiro arrecadou. Rio de Janeiro um pouco mais artificial porque foi a Caixa que comprou tudo. São Paulo foi em mercado mesmo. Mostra que o mercado acreditou, veja bem, isso é uma coisa importante, quer dizer, alguém acreditou em um instituto jurídico inédito, foi capaz de gastar bilhões em uma coisa incerta que ninguém nunca tinha feito na face da terra e a prefeitura arrecadou isso. Foram feitas lá principalmente as operações, Faria Lima e Água Espraiada, depois outras que não acompanhei muito de perto, mas sei que tem grandes inovações. Principalmente Água Branca, tem conceitos novos muito importantes, mas, enfim, estamos nos atendo aqui ao Estatuto da Cidade.

Agora, eu acho que o grande ponto falho é o Plano Diretor, que ficou muito insatisfatório no Estatuto da Cidade, ficou muito vago. Eu estava até revendo, até mesmo um inciso muito vago, que dizia que o plano diretor deve definir as áreas de restrição ou de fomento à urbanização, que é esse macrozoneamento atualmente adotado em muitos municípios, não entrou no Estatuto. $\mathrm{O}$ que entrou como definição do Plano Direto no Estatuto da Cidade? Os próprios instrumentos que ele inventou: a outorga onerosa, o direito de preempção etc. Ficou de fora tudo o que havia antes e continuou a existir, como o que a gente chama historicamente (em São Paulo, pelo menos) de lei de zoneamento. E todo mundo falando em Plano Diretor no Brasil inteiro como se fosse exatamente a mesma coisa! Depois eu fui estudar um pouco melhor e cheguei a essa proposta da tipificação que eu defendo desde 2013. O que é a questão da tipificação? Se você pegar a imensa maioria dos países que tem direito urbanístico bem organizado, você vê que existe uma definição clara não só do Plano Diretor, mas de todos os planos: quais são os planos, o que realmente é conteúdo obrigatório deles, não em uma expressão só verbal, retórica, mas inclusive numa escala de normalização. Quer dizer, você sabe tecnicamente o que tem que ter em um plano urbanístico, e a questão das escalas. Essa é uma crítica que eu faço à própria Constituição, que não deveria ter falado em plano diretor, mas em planos urbanísticos, porque daí você tem um sistema. Como ela só falou de plano diretor, criou um grande nó para os juristas, porque às vezes você tem só uma intervenção lá num pedacinho da cidade, você tem os planos de bairro, você tem coisas que não são da cidade inteira. Nós não temos um nome para isso, não temos um plano para isso.

Betânia Alfonsin - Como tem na Colômbia, né? Os planos que são "em cascata" como eles dizem.

Victor Carvalho Pinto - Então, justamente, porque a Colômbia tipificou os planos, exatamente isso. Passa batido quando a gente ouve um colombiano falando, porque a gente está interessado mais na ação. Mas quando eles estão falando "não, porque aqui foi aprovado o plano parcial de não sei o que."

Betânia Alfonsin - Exatamente, os planos parciais.

Victor Carvalho Pinto - Então o plano parcial é uma coisa muito bem explicada se você pegar a lei da Colômbia, gasta muita informação magnética, muito papel para explicar o que é um plano 
parcial. Não adianta você falar assim, "ah, o plano parcial vai cuidar de uma escala intermediária”, não, não é isso, tem que realmente definir. E depois que você definiu cada plano, você proíbe tudo que está fora do plano, essa é outra parte importante, que é a reserva do plano. Porque não adianta você regulamentar bem cada plano e falar assim, "não, mas na hora que eu quiser eu faço uma coisa que não é nenhum desses planos." Daí não adianta nada, você não tem um sistema. Então eu acho que a gente não conseguiu criar um sistema de planejamento no Brasil. A gente gasta, sei lá, um ano e pouco discutindo o plano diretor e aí antes, durante ou depois vem uma lei qualquer pontual e muda alguma coisa importantíssima para a cidade, ou a prefeitura faz uma obra importantíssima para a cidade e aí, quando você reclama, falam que "não tem nada a ver com o plano diretor." Não conseguimos criar a reserva de Plano. A partir daí, não vejo como sair do caos, entende? Porque aí vale tudo, o sistema político e a corrupção toma conta, porque aí é o casuísmo.

Betânia Alfonsin - Nós queríamos que você falasse um pouco sobre o arranjo federativo brasileiro e essa aposta que a Constituição fez nos municípios como um ente da Federação que vai executar a política urbana. Como que você vê isso, como que você vê a questão da região metropolitana, a questão da aprovação do estatuto da metrópole nesse caminho dos vinte anos, como você está vendo tudo isso vinte anos depois? Essa aposta que o constituinte fez no ente municipal ainda é válida?

Victor Carvalho Pinto - Olha, eu tenho uma interpretação diferente da Constituição com relação a esse assunto. Vejo assim: legislar sobre o direito urbanístico, artigo 24, é competência concorrente de quem? União, Estado e Distrito Federal. Não tem o município ali no artigo 24. Aí vamos lá para o artigo 30, do município, que fala em “ordenar o território”, prerrogativa única do município. Eu leio da seguinte maneira: uma coisa é legislar sobre direito urbanístico, outra coisa é ordenar o território, são coisas diferentes. Para mim, ordenar o território é elaborar e executar os planos. Legislar sobre o direito urbanístico é estabelecer essas regras gerais: o Estatuto da Cidade, regulamentação ou a criação de novos institutos jurídicos em abstrato. Na minha visão, a Constituição propôs um modelo que é o que existe no mundo inteiro. Talvez só nos Estados Unidos exista tanta liberdade para o município quanto no Brasil, talvez um pouco menos. Mas na maior parte do mundo ou o governo nacional ou as províncias e estados nas federações é que fazem a grande legislação urbanística. Na Espanha, por exemplo, a competência passou do governo nacional para as regiões autônomas. A legislação mais densa, que eu costumo chamar de "código de urbanismo", como se denomina em alguns países, é uma legislação provincial. Se você for ver nos Estados Unidos não existe lei nacional de urbanismo, existem leis estaduais. No Canadá eu acho que também. No México tem uma lei nacional, mas depois as províncias é que detalham. Acho que na Argentina também é só provincial. Então nas Federações o normal é que os Estados assumam essa função, que no nosso caso aqui seria, por assim dizer, regulamentar o Estatuto da Cidade. Quer dizer, grande parte do que eu critico no Estatuto poderia ser, corrigido por uma regulamentação estadual, sem precisar revogar o Estatuto ou fazer por lei federal. Então eu vejo o modelo da Constituição nesse sentido. Se você pegar o artigo 24, está claro ali que a União deveria fazer só as regras gerais, e a regra, digamos assim, mais definitiva, mais detalhada, seria dos Estados. Mas não era a nossa cultura anterior à Constituição e continua não sendo. Que eu saiba, só os três Estados do Sul é que fizeram leis estaduais, mesmo assim ainda muito limitadas.

Sem dúvida que o município é quem faria o próprio plano diretor e os demais planos urbanísticos. Aí eu acho que não tem muito como fugir, quer dizer, também no mundo inteiro é o município que faz 
isso. Mesmo nos países mais centralizados, sempre vai ser o município que vai fazer o urbanismo. $\mathrm{O}$ que a gente poderia questionar é que em muitos países o plano é feito pelo município e aprovado pela província, pelo menos os planos mais importantes, o que no Brasil não seria possível.

Eu acho o municipalismo enquanto tal, como a gente pratica no Brasil um fator de atraso, lamento dizer isso, eu sei que grande parte de nós somos municipalistas, mas da maneira como a gente costuma tratar esse assunto, eu vejo como um fator negativo. Eu vejo os municípios em três categorias hoje em dia, geograficamente. Você tem o município pequenininho que está lá no interior do Brasil, você tem o município médio e você tem o município que está dentro de uma região metropolitana. E o único município que de certa maneira cumpre as funções que a gente supõe que os municípios devam sempre cumprir é o médio, que não está em região metropolitana. Por quê? Porque ele tem uma certa administração pública razoável, ele tem os funcionários, ele tem uma sociedade civil, ele tem algum grau de organização da máquina, mas ele não depende dos vizinhos porque ele está geograficamente ele está isolado, a zona urbana dele está isolada. Então ele pode fazer tudo aquilo que a gente acha que um município tem que fazer. Agora, os municípios lá do "interiorzão", aí a gente tem que fazer uma grande discussão constitucional que vai muito além do direito urbanístico, pois muitos deles são uma espécie de farsa. Eles simplesmente não existem enquanto máquina, não têm funcionário público, não têm site na internet, não têm tecnologia da informação, enfim, eles não existem. Dos 5570 municípios existentes, deve ter uns 5000, mais ou menos, que estão nessa categoria. Isso vai muito além do nosso assunto aqui, mas eu vejo que o estado membro deveria ter uma presença muito maior nessas regiões afastadas, de baixa densidade demográfica. Também não acho que é a União que tem que estar. Eu trabalho com o conceito do território estadual, análogo ao território federal que está na Constituição, como os antigos territórios, Roraima, Rondônia, Acre, que são áreas que não são Estados, pertencem à União, mas não têm a autonomia de Estado. Eu acho que a gente poderia ter umas áreas que pertencem ao Estado, mas não tem autonomia de município. Quer dizer, o negócio ficou com tão baixa densidade que o Estado cuida daquilo diretamente. Insistir nessa tese da autonomia municipal para todos os centímetros do Brasil, eu acho realmente uma loucura. Imagine esse pessoal recebendo dinheiro e prestando contas, quando em grande parte desses municípios, não tem ninguém com nível superior. O grau de distância cultural de nós que vivemos aqui no centro é muito grande. Se cair uma auditoria ali, fatalmente vão dizer que não prestaram contas. Tem muito prefeito condenado por improbidade administrativa simplesmente por incapacidade de administrar, fazer uma licitação com todas as exigências da lei, fazer um concurso, enfim.

E nas regiões metropolitanas, aí por motivos opostos, o municipalismo tradicional também não funciona. Esses municípios têm uma razoável capacidade, mesmo quando pequenos, mas a conurbação impede você de imaginar que tudo aquilo que a gente atribuiu ao município seja feito realmente pelo município. Não tem como. A gente tem que reconhecer que muitas funções, importantíssimas, que normalmente seriam municipais, não vão ser mais municipais, elas vão ser metropolitanas. E a gente não conseguiu no Brasil equacionar essa expressão metropolitana. Até algum tempo atrás, isso era sinônimo de Estadual, falava "metropolitano" era Estadual. Os estados tinham secretarias metropolitanas, empresas metropolitanas, conselhos metropolitanos. Então na prática significava estadual com, digamos assim, uma governança um pouco municipalista no sentido de que os municípios eram convidados a participar e nomear alguém para o conselho, mas no fundo, era estadual. Depois do acórdão 
do Supremo ${ }^{4}$ e do Estatuto da Metrópole, não é mais correto dizer que isso é aderente à Constituição. O que está colocado hoje é uma governança interfederativa. Só que essa tal governança interfederativa, ninguém conseguiu botar de pé. E o pior é que as pessoas já desistiram de tentar botar de pé, porque logo depois do Estatuto da Metrópole teve um oba- oba e isso foi morrendo. O IPEA ainda tem um pessoal que discute isso, mas a gente vê que foi morrendo e ninguém mais fala do assunto.

Até por curiosidade eu vou contar para vocês, eu participei de uma discussão com a equipe do tribunal de contas do Estado de Minas Gerais que está fazendo uma auditoria sobre a Lagoa da Pampulha. Essa lagoa recebe poluição do município de Contagem e o município de Belo Horizonte gasta uma fortuna todo ano para despoluir, porque a lagoa é patrimônio da humanidade, tombada pela UNESCO e o grande ponto turístico da cidade. O tribunal de contas resolveu fazer uma auditoria e chegou à conclusão de que o problema é metropolitano. É chocante você perceber como absolutamente nada funciona, você não tem uma reunião metropolitana, você não tem uma decisão metropolitana, você não tem um conselho metropolitano, o Plano Diretor é muito vago, não fala nada sobre o assunto. Tem uma minuta de PDUI já elaborada, depois de longa discussão. Então a meu ver essa situação é o retrato do Brasil e olha que Belo Horizonte é um dos lugares mais bem institucionalizados em matéria de região metropolitana, porque tem agência metropolitana, tem funcionários etc. E no resto é pior, não sei como está Porto Alegre, mas, em São Paulo eu acho que foi todo desmontado.

Nelson Saule Júnior - É uma tragédia.

Victor Carvalho Pinto. Eu tenho conversado com muita gente sobre desenvolvimento urbano em geral e gosto muito de conversar com os estrangeiros porque eles têm uma visão mais holística do Brasil. Vários me falaram, "olha, o grande problema brasileiro é metropolitano", o grande problema de desenvolvimento urbano do ponto de vista institucional é botar ordem em região metropolitana, porque realmente é um caos, é muita gente que mora nessas áreas. Nos estudos jurídicos, aparece como uma nota de rodapé de direito constitucional. A gente pode gastar horas e horas falando de município, de federação e o metropolitano não vai ser nem quinze minutos em um curso de graduação. Só que $50 \%$ da população brasileira mora em região metropolitana. Então o verdadeiro instituto jurídico que deveria estar sendo estudado é a região metropolitana.

Victor Carvalho Pinto - Sobre o Estatuto da Metrópole, até poucos anos antes de ser editado, todo mundo achava que era inconstitucional ter uma lei federal sobre essa matéria. Teve várias outras discussões no Congresso que sempre eram barradas por isso. Aí, enfim, teve o projeto, o deputado Zezé assumiu a relatoria e liderou esse processo, fez um projeto bacana, mas um pouco genérico demais, embora eu também não considere que lei federal vai resolver. A Constituição mandou as assembleias fazerem, então tem que cobrar das assembleias, dos governos estaduais. O próprio Supremo, na época que saiu aquele acórdão, eu tive a oportunidade de participar de um evento público com o ministro Gilmar Mendes, um evento sobre saneamento, e eu perguntei para ele: ministro, o senhor está falando que tal coisa não pode, mas como é que vai funcionar realmente no mundo dos fatos? Ele falou: "ah, isso aí não cabe ao Supremo dizer, isso aí os Estados, cada um tem que fazer do seu jeito". O problema é que os Estados não têm coragem de fazer as coisas. Eu vejo que a gente poderia ter várias soluções com vários graus de intervenção. Hoje em dia eu defendo uma coisa que é o mínimo, anuência, que 
é um termo que está lá na lei 6776 para os loteamentos, o que eu vejo, hoje, como uma solução sábia. Para você ver, lá em 1979, eles falaram o seguinte: "se está em região metropolitana, o loteamento tem que ter anuência metropolitana”. Bom, é a coisa mais básica. Não é nem licenciamento, não é nem plano, nem obra, nem nada, só anuência. Para mim isso aí é o mínimo que a gente teria que exigir para as grandes coisas metropolitanas. Então o município está lá, vai fazer um metrô, o Estado vai fazer o metrô, bom, tem que passar por uma anuência no conselho metropolitano. Vai ter a concessão de saneamento metropolitano, tem que passar por uma anuência, é o mínimo do mínimo. É uma coisa que não gasta um tostão furado, é só chamar a reunião e votar. O PAC vai financiar uma série de obras como financiou aí, quando a gente estava com dinheiro na mão, em mobilidade urbana, um monte de coisa, em Programa Minha Casa Minha Vida, um monte de dinheiro que foi gasto. Busca anuência, passa lá o conjunto habitacional para ter uma anuência metropolitana. Enquanto você não tem uma governança mais sofisticada, que seria o planejamento, garante no mínimo a anuência, porque a anuência quem vai executar continua sendo o município ou o Estado. Você não precisa criar um outro órgão para executar. Então é muito mais simples, chama o conselho, o conselho recebe, designa um relator, tem um estudo técnico e depois o pessoal vota lá, com a ponderação que existir de acordo com a lei e aprova ou não aprova aquela intervenção. E digo mais: os próprios planos diretores, no mínimo, têm que passar por uma anuência metropolitana. Pega a minuta, manda lá para o órgão, o conselho metropolitano vai discutir e vai falar "não, não temos nada contra esse plano diretor, estamos de acordo, segue em frente". Independente do PDUI.

Nelson Saule Júnior - Quais você entende que sejam os principais obstáculos e que ações são necessárias para o Estatuto das Cidades ser implementado com maior efetividade nas cidades? Na sua opinião qual é o estágio do direito urbanístico brasileiro? De que forma o Estatuto da Cidade pode contribuir para a disseminação, consolidação do direito urbanístico aqui no Brasil?

Victor Carvalho Pinto - Para mim, o Estatuto da Cidade é uma das leis que a gente tem em um cipoal legislativo. Claro que é, ideologicamente, a mais importante, principalmente porque tem aquelas diretrizes do artigo $2^{\circ}$. Mas hoje em dia, eu considero a lei de parcelamento do solo é tão importante quanto o Estatuto da Cidade. E, de certo modo, ela é mais aplicada do que o Estatuto da Cidade porque, bem ou mal, o parcelamento acontece e quando não é invasão, de alguma maneira estão seguindo a lei. $\mathrm{O}$ Decreto-Lei 3365, sobre de desapropriação por utilidade pública, é de uma importância extraordinária. $\mathrm{Eu}$ trabalho com o conceito de que a gente pode melhorar a institucionalidade do desenvolvimento urbano, pelo Estatuto da Cidade ou não. Com isso eu quero dizer o seguinte: grande parte do direito urbanístico está fora do Estatuto da Cidade. Para além dessas leis que eu citei, tem a regularização fundiária que também está fora. E tem no mínimo 50\% do direito urbanístico brasileiro que não está em nenhuma lei federal, certo? Que é licenciamento, código de obras, enfim, regulamentações municipais. Então a gente também tem que se abrir para isso, entender e estudar isso. Eu acho que o foco só no Estatuto da Cidade às vezes canaliza demais uma energia que é limitada que é a nossa, dos juristas, para algumas poucas questões que todo mundo tem muito interesse e deixa ao largo muita coisa importante que ninguém está estudando.

De todo modo, por mais que eu tenha uma série de ideias para melhorar o direito urbanístico, acho que o ponto maior de estrangulamento é capacidade de gestão. A gente poderia fazer o melhor direito urbanístico do mundo e provavelmente não iria ter grande impacto, porque a nossa capacidade 
de gestão é muito ruim. E isso passa por muita coisa, quer dizer, a nossa administração pública, ela é setorializada e cada setor, além de tudo, é loteado politicamente por partidos diferentes, e não tem uma institucionalidade transversal. Não tem uma institucionalidade para recursos hídricos satisfatória e nem para ordenamento territorial. O meio ambiente é meio transversal, mas só funciona quando é para barrar. Quando é para organizar e ordenar, ele não funciona muito bem. Só para licenciar e impedir o mau desenvolvimento, então o ambiente funciona bem. Uma institucionalidade transversal seria o conceito de ordenamento territorial no sentido mais amplo, além do urbanístico, um ordenamento territorial completo do país. A gente não tem e não sabe nem como organizar a máquina para fazer isso funcionar. Nos municípios e nos Estados, o urbano é só mais uma secretaria que não tem ascendência sobre as outras. Inclusive na cabeça das pessoas, o planejamento urbano é para controlar só o privado, só controla a propriedade privada. A intervenção pública, na cabeça de muita gente, não está subordinada ao planejamento urbano. Na hora que um secretário de obras vai fazer uma avenida e chega o secretário do urbanismo e fala: "não, não é para você fazer avenida", ele fala: "quem você pensa que é? Eu sou o secretário de obras do município, eu quero fazer a avenida, eu vou fazer a avenida e você não tem nada a ver com isso". E isso acontece cotidianamente. A habitação também, quer dizer, "ah, vou fazer habitação mal localizada, enfim" e o cara do urbanismo fala: "não, não é para você fazer habitação aî", "não, mas eu sou o secretário de habitação, eu faço habitação onde eu quiser, você cuida lá do teu, mas o meu você não mexe". E nós achamos isso normal. Então a gente não exige licenciamento dessas obras públicas, a gente acha que licenciamento é só para obra privada. Então é uma coisa mal resolvida.

Nós não temos sequer um modelo gerencial de como tratar esse assunto. A gente não tem sequer um paradigma, um município que tenha organizou a máquina de uma maneira que funcione. Até onde eu vejo todo mundo reclama do mesmo fenômeno. Talvez fosse o caso de fazer uma pesquisa dos melhores municípios e ver se eles estão bem organizados, talvez em Curitiba a coisa seja melhor, não sei. Tenho uma certa esperança na tecnologia da informação. Sempre evitando qualquer tipo de solução mágica, mas hoje em dia com a tecnologia da informação avançando como ela avançou, não é correto a gente pensar em fazer urbanismo e desenvolvimento urbano sem essas coisas básicas, tipo cartografia georeferrenciada, geoportais em que o cidadão consegue entrar lá e ver o que, qual é a regulação para o bairro dele, essas várias camadas que a gente coloca em cima do mapa. Eu acho que isso aí, realmente, a gente deveria colocar como prioridade número um. Assim, hoje em dia um município que não tem isso, eu já acho errado ele fazer plano diretor. A prioridade deveria ser colocar ordem na casa, na informação. Vale também para o cadastro técnico multifinalitário, para colocar ordem nessa bagunça dos cartórios. Toda a questão da cartografia é extremamente bagunçada.

Hoje em dia eu valorizo muito as teses levantadas pelo Luiz Ugeda, que é geógrafo e advogado que defende muito a institucionalização da cartografia. Isso vai além do urbanismo, é toda a cartografia. Quando você o vê explicando como isso funciona em vários países do mundo, percebe que nós estamos realmente em um nível de absoluto atraso. Um país pobre, como a Indonésia, criou uma agência de regulação da cartografia e botou em ordem a cartografia no país há poucos anos atrás. Então não é negócio que só país rico pode fazer, não. Claro, muitos municípios já estão fazendo, mas aí falta um pouco de institucionalização para você padronizar o que cada um faz e poder depois juntar as várias cartografias dos vários municípios e as escalas municipais, estaduais e federal. As concessionárias do serviço público fazem seus mapas, depois não tem como integrar isso porque não tem padronização. 
E aí sim a União e os Estados deveriam estar financiando isso para os municípios, principalmente os do interior. Acho que o melhor gasto que o dinheiro federal poderia ter é tecnologia da informação, cartografia, banco de dados, cadastros. É uma área que eu não conheço bem, mas suponho que exista software de planejamento urbano propriamente dito, que poderia estar sendo oferecido de graça para os municípios.

Vale para tributação também. Essa bagunça que são o nosso IPTU e ITBI. Hoje em dia você tem redes neurais que pegam grandes bancos de dados e já vão estimando o valor dos imóveis. A gente poderia ter um salto de qualidade, sem grandes ilusões, mas no mínimo permitiria os municípios terem um pouco mais de condições de fazer e o cidadão ter acesso à informação, porque isso vale para os dois lados. Na hora que você bota a administração pública dentro da tecnologia da informação, você abre uma forma de consulta para o cidadão, aí muda essa situação, porque hoje em dia é tudo muito chutado, muito achado. "Eu acho que a cidade isso, eu acho que a cidade aquilo, o meu bairro isso ou aquilo". Então, se você tiver informação mais disseminada, você vai criando uma cultura de o cidadão abrir o celular ou o computador dele e verificar em tempo real o congestionamento do trânsito, a criminalidade, a poluição, etc. Tenho visto coisas maravilhosas em matéria de georreferenciamento de dados. Você vê onde está calor na cidade, onde tem verde, onde não tem. Aí você tem condição de criar uma cultura cidadã um pouco mais informada também.

Betânia Alfonsin - Excelente entrevista. Obrigada, Victor!

Nelson Saule Júnior - Obrigado, Victor. 